\title{
Improvement of Chromatographic Detection Unit
}

\author{
Gang-qiang XIA ${ }^{\text {a }}$, Gao-ming WANG ${ }^{\text {b }}$
}

\author{
NARI Technology Co., Ltd. Integrity Avenue on the 19th, Jiangning District, \\ Nanjing City, Jiangsu, china \\ axiagangqiang@sgepri.sgcc.com.cn, bwanggaoming@sgepri.sgcc.com.cn
}

\begin{abstract}
Keywords: Dissolved gas analysis; on-line monitoring; double-column-double detector module; linear response.
\end{abstract}

Abstract. The separation and detection modules of the chromatographic system for the transformer gas-in-oil on-line monitoring is improved. The former single-column separation detection module is improved to double-column separation detection module, and compared with single-column detection module. The results show that the double-column detection module has a better separation performance and the separation process could be completed within $13 \mathrm{~min}$. The new detector has a linear response for all the fault gases in the whole detection range, which greatly reducing the workload and calibration time. The system exhibited good stability and high accuracy. The deviation of repeated test is less than 5\%, and the deviation from off-line measurement is less than $15 \%$.

\section{Introduction}

Transformer is one of the most important equipment in power system. Latent fault of equipment (whether thermal fault or electrical fault) will eventually lead to the breakdown of insulating oil to generate various characteristic gases. The composition, content and gas yield of the gases can reflect the degree of aging or failure of transformer insulation. It has become one of the relatively mature, effective and widely used methods in the power sector ${ }^{[1-5]}$; the Dissolved Gas Analysis with gas chromatography (DGA) has played an indisputable role in various types of transformer failures detection ${ }^{[6]}$. On-line monitoring device based on DGA principle can monitor the dissolved gas content of each component in each state, through cooperation with alarm settings and expert analysis system, timely capture the symptom information of the accident ${ }^{[7]}$.

Based on DGA, aiming at the problems on efficiency in separation, low accuracy and time-consuming calibration of the original mode, a new mode developed. Improve the on-line monitoring device and improve the actual production commissioning efficiency.

Transformer oil on-line monitoring system. Transformer oil on-line monitoring system consists of several components such as oil and gas separation system, mixed gas separation, gas detection, data processing, fault diagnosis and environmental control ${ }^{[8]}$. The monitoring process is that the transformer oil circulated enters the degassing device, separatedthe dissolved gas, then gas separated into single component by sseparation system, followed by the gas sensor to generate response signals, according to the response characteristics of each single gas, recorded the response signal, Through the comparison with alarm settings and expert analysis system to draw conclusions.

The principles of Gas separation and detection. Due to the different adsorption and desorption rates, time for each component to pass through the column is different, so that to achieve the purpose of separating to single component gas; the separated single component gas contacts the gas sensor in turn, gas sensor responded, so as to realize the detection of dissolved gas.

Single-column separation detection module. Single-column separation detection module choose a composite column ideally achieved Gas separation in a short time, followed by gas sensors to detect each component gas: composite column selection HY02 (Nanjing wushu Chemical Co., Ltd.); gas sensor selection $\mathrm{SnO}_{2}$ semiconductor type sensor TGS813 (Nanjing wushu Chemical Co., Ltd.); for $\mathrm{CO}_{2}$ TGS813 no response, used T6615 (SHENZHEN GWILDG ELECTRONIC CO.LTD) detecte $\mathrm{CO}_{2}$, the process shown in Fig. 1. Mixed gas is separated and detected in order of $\mathrm{H}_{2}, \mathrm{CO}, \mathrm{CH}_{4}, \mathrm{C}_{2} \mathrm{H}_{4}$, $\mathrm{C}_{2} \mathrm{H}_{6}, \mathrm{C}_{2} \mathrm{H}_{2}$ and $\mathrm{CO}_{2}$. 


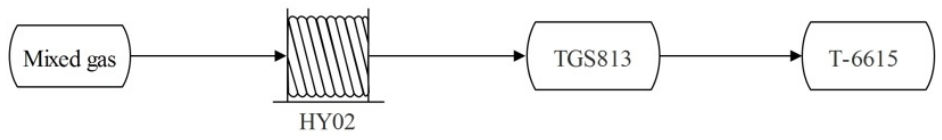

Fig.1 Single-column module flowchart.

Under the premise of ensuring sufficient separation, the higher column temperature, the shorter the analysis time, but the peak shape is distorted, the lower the column temperature, the better the resolution, but the longer analysis time; The higher pre-column pressure, the shorter analysis time, but the lower resolution, The lower the column pressure, the better resolution, But analysis time increases; Considering all, select column temperature is $65^{\circ} \mathrm{C}$ and pre-column pressure is $0.12 \mathrm{Mpa}$. Consider of the Peak area, the length of the column, the thickness, select injection volume of $2 \mathrm{~mL}$.

Double-column separation detection module. Based on the single-column module, replace the column with two columns, followed by a gas sensor at each column. Columns are selected HY05-A, HY05-B; gas sensors are selected WS600 (column and sensor are Nanjing Wushu Chemical Co., Ltd.). The process is shown in Fig.2: mixed gas is separated and detected in order of $\mathrm{CH}_{4}, \mathrm{CO}_{2}, \mathrm{C}_{2} \mathrm{H}_{4}$, $\mathrm{C}_{2} \mathrm{H}_{6}, \mathrm{C}_{2} \mathrm{H}_{2}, \mathrm{H}_{2}$ and $\mathrm{CO}$.

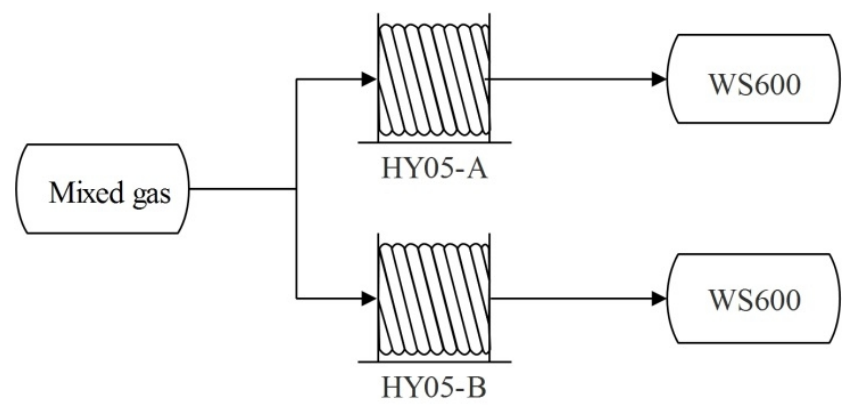

Fig.2 Double-column module flowchart.

\section{Results and Discussion}

Separate chromatographic peaks of the detection module. By testing two separations detection module, shown in Fig.3, both can make the mixed gas separated into single-component gas and detected. Single-column module end time about $25 \mathrm{~min}$, double-column module end time about 13min; single-column module $\mathrm{H}_{2}, \mathrm{CO}$ and $\mathrm{CH}_{4}$ separation is low, the separation effect is poor; double-column module has Better separation effect.

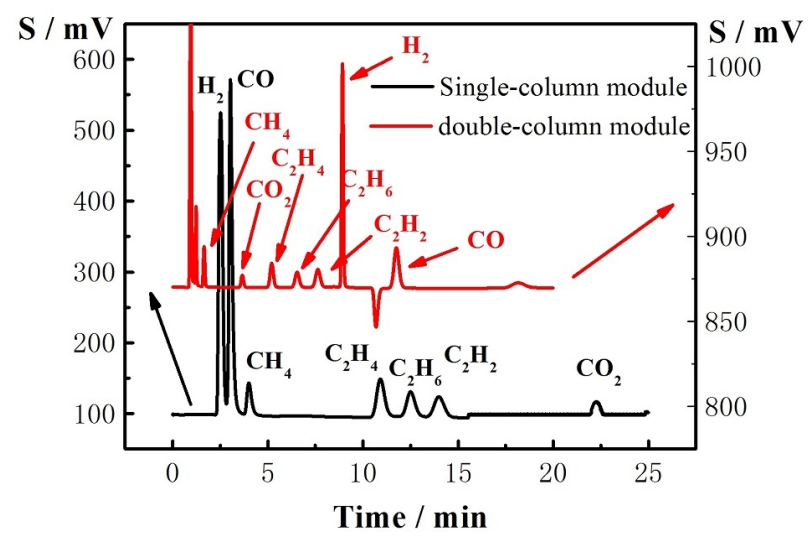

Fig.3 The chromatograms of the two modules.

Repeatability.Fig.4 shows the performance of two modules for $\mathrm{H}_{2}\left(1650 \mathrm{mg} / \mathrm{m}^{3}\right), \mathrm{CO}\left(1487 \mathrm{mg} / \mathrm{m}^{3}\right)$, $\mathrm{CO}_{2}\left(3300 \mathrm{mg} / \mathrm{m}^{3}\right), \mathrm{CH}_{4}\left(223 \mathrm{mg} / \mathrm{m}^{3}\right), \mathrm{C}_{2} \mathrm{H}_{4}\left(123 \mathrm{mg} / \mathrm{m}^{3}\right)$ and $\mathrm{C}_{2} \mathrm{H}_{2}\left(145 \mathrm{mg} / \mathrm{m}^{3}\right)$ response repeatability test curve, from the figure, the two modules all have a good response repeatability. 


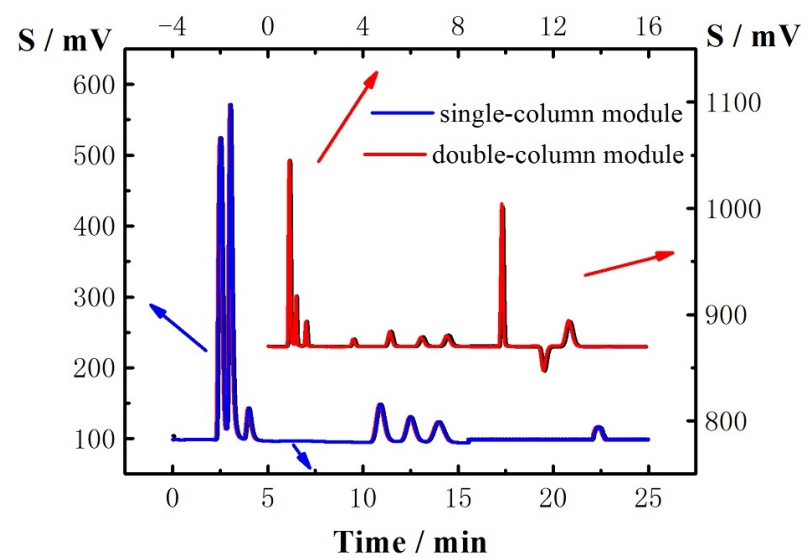

Fig. 4 The test repeatabilities of the two modules.

Stability. Based on good repeatability, the stability test is tested. The results shown in Fig.5, in which (a) shows the stability of single-column module, $\mathrm{H}_{2}$ and $\mathrm{CO}$ use the right ordinate, and the rest use the left; (b) shows the stability of double-column module, $\mathrm{H}_{2}$ use the right ordinate, the rest use the left.from the figure: both the modules have long-term good stability; the deviation of single-column module is within $10 \%$ and double-column module is within $5 \%$; double-column modules have better long-term stability.
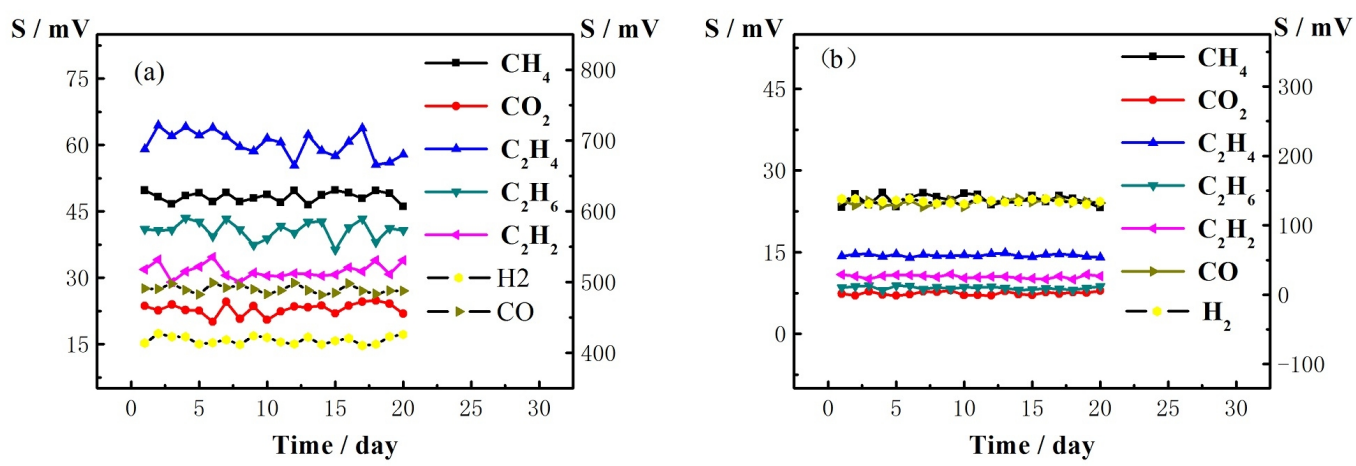

Fig.5 Stability test of Single-column module (a) and Double-column module (b).

Response of Separation of detection module. The two modules were loaded in on-line monitoring device for measuring samples. samples are prepared by JHBY-01 (Changzhou City, Jiahua Electronics Co., Ltd.) and measured by laboratory gas chromatography ( zhongfen-2000B :Henan Instrument Co., Ltd.). Fig. 6 shows two devices response curve for different concentrations measurement, entire measurement range, and single-column module for the gas response are non-linear response; although the double-column module reduces the response sensitivity, clearly see the linear response relationship. The non-linear response makes the device time-consuming and difficult to calibrate ${ }^{[9-11]}$. Double-column module can greatly reduce the workload and time of device calibration and improve the accuracy of the device. 


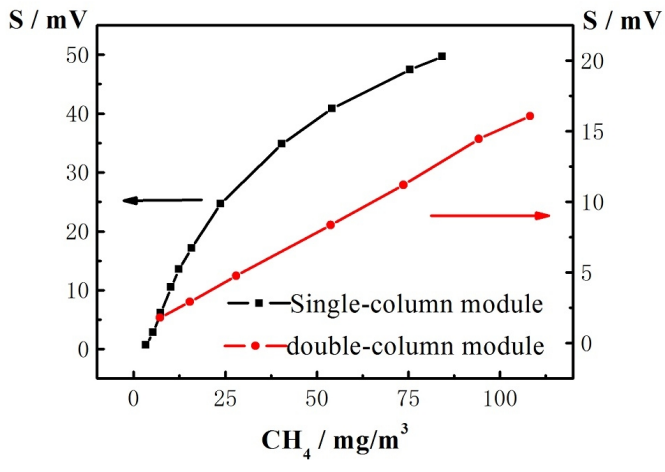

( a ) $\mathrm{CH}_{4}$ response curve.

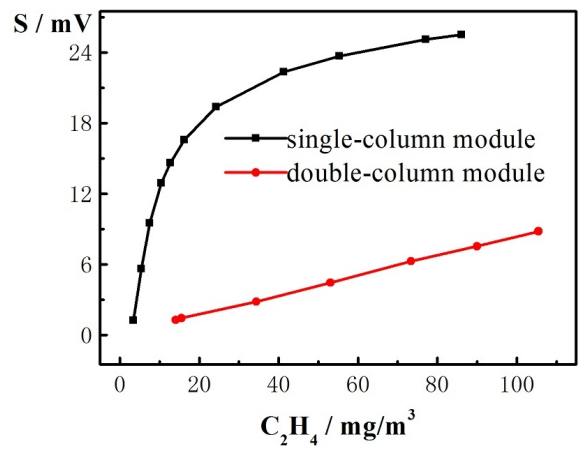

( c ) $\mathrm{C}_{2} \mathrm{H}_{4}$ response curve.

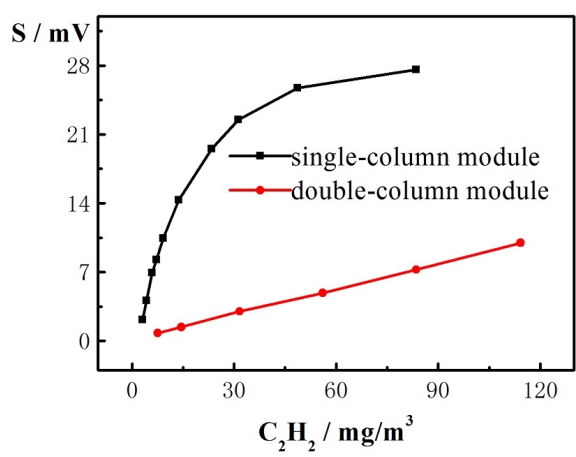

( e ) $\mathrm{C}_{2} \mathrm{H}_{2}$ response curve.

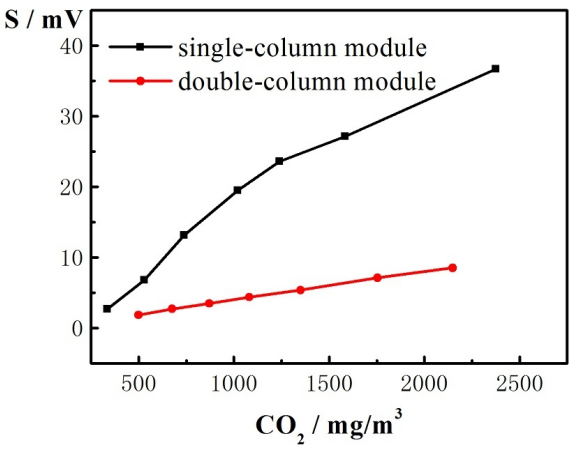

( b ) $\mathrm{CO}_{2}$ response curve.

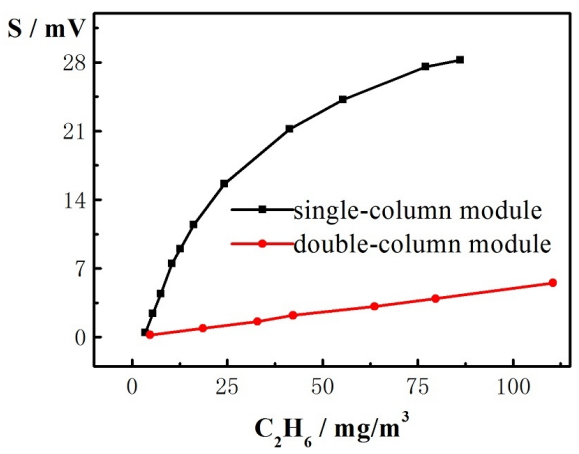

( d ) $\mathrm{C}_{2} \mathrm{H}_{6}$ response curve.

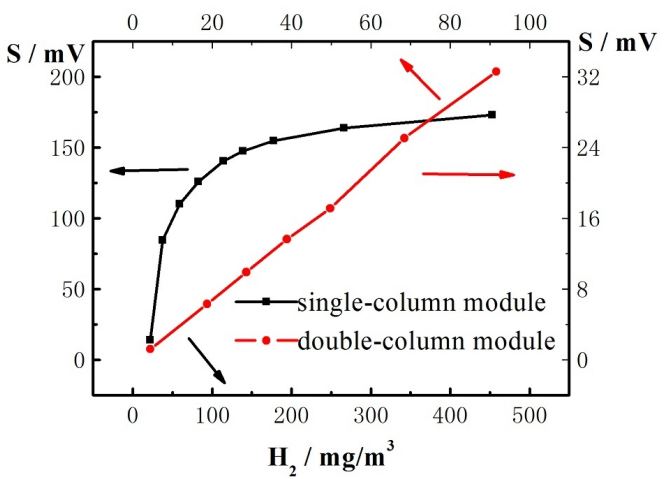

( f ) $\mathrm{H}_{2}$ response curve.

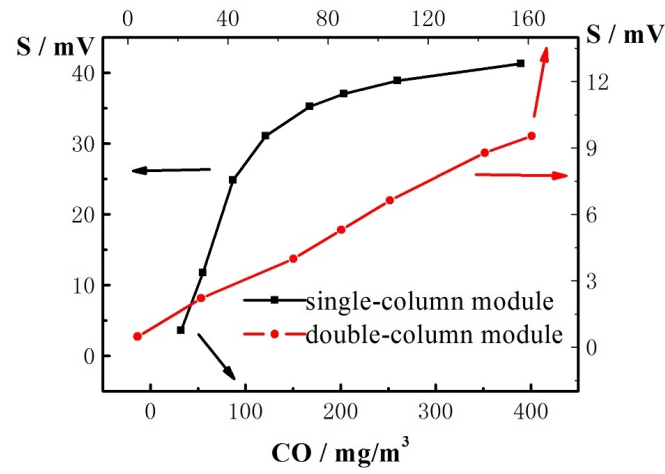

( g ) CO response curve.

Fig.6 Response curves of the two modules for the fault gases.

Online monitoring device tests. Test two modules on-line monitoring device accuracy. Samples measured by on-line monitoring devices and laboratory gas chromatography, and calculation the 
relative measurement error of devices dates and laboratory dates, measurement devices accuracy, measurement error according to Eq. 1 calculated.

$$
\text { Measurement error }=\left|\frac{\text { devices dates }- \text { laboratory dates }}{\text { laboratory dates }}\right| \times 100 \%
$$

Measurement error results are shown in Table 1 and Table 2. Seen from the table: measurement error of the single-column module is within $30 \%$ and double-column module is within 15\%; the double-column module has higher accuracy.

Tab.1 Measurement error of single-column module.

\begin{tabular}{cccc|ccc|ccc}
\hline & \multicolumn{3}{c|}{ Low concentration } & \multicolumn{3}{c|}{ Medium concentration } & \multicolumn{3}{c}{ High concentration } \\
\hline & $\begin{array}{c}\text { devices } \\
\text { dates } \\
{\left[\mathrm{mg} / \mathrm{m}^{3}\right]}\end{array}$ & $\begin{array}{c}\text { laboratory } \\
\text { dates } \\
{\left[\mathrm{mg} / \mathrm{m}^{3}\right]}\end{array}$ & $\begin{array}{c}\text { measurement } \\
\text { error } \\
{[\%]}\end{array}$ & $\begin{array}{c}\text { devices } \\
\text { dates } \\
{\left[\mathrm{mg} / \mathrm{m}^{3}\right]}\end{array}$ & $\begin{array}{c}\text { laboratory } \\
\text { dates } \\
{\left[\mathrm{mg} / \mathrm{m}^{3}\right]}\end{array}$ & $\begin{array}{c}\text { measurement } \\
\text { error } \\
{[\%]}\end{array}$ & $\begin{array}{c}\text { devices } \\
\text { dates } \\
{\left[\mathrm{mg}^{3} \mathrm{~m}^{3}\right]}\end{array}$ & $\begin{array}{c}\text { laboratory } \\
\text { dates } \\
{\left[\mathrm{mg}^{2} \mathrm{~m}^{3}\right]}\end{array}$ & $\begin{array}{c}\text { measurement } \\
\text { error } \\
{[\%]}\end{array}$ \\
\hline $\mathrm{CH}_{4}$ & 5.23 & 4.47 & 17.00 & 14.53 & 17.32 & 16.11 & 80.06 & 92.03 & 13.01 \\
$\mathrm{CO}_{2}$ & 594.44 & 549.01 & 8.27 & 864.24 & 1120.85 & 22.89 & 1545.25 & 1275.56 & 21.14 \\
$\mathrm{C}_{2} \mathrm{H}_{4}$ & 4.24 & 4.79 & 11.48 & 14.44 & 16.65 & 13.27 & 94.22 & 78.51 & 20.01 \\
$\mathrm{C}_{2} \mathrm{H}_{6}$ & 2.64 & 3.12 & 15.38 & 12.86 & 16.45 & 21.82 & 78.27 & 62.75 & 24.73 \\
$\mathrm{C}_{2} \mathrm{H}_{2}$ & 2.14 & 1.91 & 12.04 & 12.54 & 15.47 & 18.94 & 24.07 & 29.64 & 18.79 \\
$\mathrm{H}_{2}$ & 2.44 & 2.06 & 18.45 & 33.28 & 39.65 & 16.07 & 74.62 & 75.23 & 0.81 \\
$\mathrm{CO}$ & 6.12 & 5.15 & 18.83 & 56.28 & 66.15 & 14.92 & 159.32 & 142.14 & 12.09 \\
\hline
\end{tabular}

Tab.2 Measurement error of double-column module.

\begin{tabular}{cccc|ccc|ccc}
\hline & \multicolumn{3}{c|}{ Low concentration } & \multicolumn{3}{c|}{ Medium concentration } & \multicolumn{3}{c}{ High concentration } \\
\hline $\begin{array}{c}\text { devices } \\
\text { dates } \\
{\left[\mathrm{mg} / \mathrm{m}^{3}\right]}\end{array}$ & $\begin{array}{c}\text { laboratory } \\
\text { dates } \\
{\left[\mathrm{mg} / \mathrm{m}^{3}\right]}\end{array}$ & $\begin{array}{c}\text { measurement } \\
\text { error } \\
{[\%]}\end{array}$ & $\begin{array}{c}\text { devices } \\
\text { dates } \\
{\left[\mathrm{mg} / \mathrm{m}^{3}\right]}\end{array}$ & $\begin{array}{c}\text { laboratory } \\
\text { dates } \\
{\left[\mathrm{mg} / \mathrm{m}^{3}\right]}\end{array}$ & $\begin{array}{c}\text { measurement } \\
\text { error } \\
{[\%]}\end{array}$ & $\begin{array}{c}\text { devices } \\
\text { dates } \\
{\left[\mathrm{mg} / \mathrm{m}^{3}\right]}\end{array}$ & $\begin{array}{c}\text { laboratory } \\
\text { dates } \\
{\left[\mathrm{mg}^{3} \mathrm{~m}^{3}\right]}\end{array}$ & $\begin{array}{c}\text { measurement } \\
\text { error } \\
{[\%]}\end{array}$ \\
\hline $\mathrm{CH}_{4}$ & 2.03 & 2.27 & 10.57 & 33.01 & 30.80 & 7.18 & 84.36 & 90.32 & 6.60 \\
$\mathrm{CO}_{2}$ & 544.05 & 549.01 & 0.90 & 1008.63 & 1143.30 & 11.78 & 1500.55 & 1620.2 & 7.38 \\
$\mathrm{C}_{2} \mathrm{H}_{4}$ & 4.44 & 4.79 & 7.31 & 52.66 & 57.07 & 7.73 & 95.52 & 100.41 & 4.87 \\
$\mathrm{C}_{2} \mathrm{H}_{6}$ & 2.86 & 3.12 & 8.33 & 45.45 & 47.76 & 4.84 & 28.07 & 32.61 & 13.92 \\
$\mathrm{C}_{2} \mathrm{H}_{2}$ & 2.00 & 1.77 & 12.99 & 46.27 & 40.78 & 13.46 & 110.03 & 101.23 & 8.69 \\
$\mathrm{H}_{2}$ & 3.58 & 3.15 & 13.65 & 39.16 & 35.03 & 11.79 & 77.82 & 75.44 & 3.15 \\
$\mathrm{CO}$ & 56.26 & 61.58 & 8.64 & 10.38 & 9.55 & 8.69 & 119.52 & 125.6 & 4.84 \\
\hline
\end{tabular}

\section{Conclusion}

The traditional DGA system has been successfully improved by a new double column and double detector module. It was found by comparative study that the column separation performance, long term working stability and detection accuracy of the improved system are obviously better than the original single column system.

\section{References}

[1] Li-jun ZHOU, Guang-ning WU and Zhi-cheng ZHOU: China Railway Science.141-144(2007).

[2] De-bing WEN, Kai LI and Hui JIANG: Electric Power: 70-73(2012).

[3] Duval M: IEEE Electrical Insulation Magazine: 6-15(2003).

[4] Guardado J L, Naredo J L and Moreno P: IEEE Transactions on Power Delivery: 643-647(2001).

[5] Jing LIU, Qing-dan HUANG: Science \& Technology Information: 45-50(2014).

[6] Guang-jun ZHANG, Zheng QIAN and Zhang YAN: Transformer: 30-34(1999).

[7]Meng-jun WANG, Qiang FU and Xue LI: Transformer: 73-75(2014).

[8] Xiao-xiao ZHAO, Yu-xin YUN, Xin-kuan WANG: Transformer: 64-68(2010).

[9] F. Gyger, M. Hu bne rand C. Feldmann: Chemistry of Materials: 4821-4827(2010).

[10] S. Zhu, D. Zhang and J. Gu: Journal of Nanoparticle Research: 1389-1400(2009). 
[11] Q. Qi, T. Zhang and X. Zheng: Sensors and Actuators B: Chemical: 36-42(2008). 